\title{
Recognition of Thermal Images of Direct Current Motor with Application of Area Perimeter Vector and Bayes Classifier
}

\author{
Adam Glowacz ${ }^{1}$, Andrzej Glowacz ${ }^{2}$, Zygfryd Glowacz ${ }^{3}$ \\ AGH University of Science and Technology, \\ Faculty of Electrical Engineering, Automatics, Computer Science and Biomedical Engineering, \\ ${ }^{1}$ Department of Automatics and Biomedical Engineering, \\ ${ }^{3}$ Department of Power Electronics and Energy Control Systems \\ Al. A. Mickiewicza 30,30-059 Kraków, Poland, adglow@agh.edu.pl, glowacz@agh.edu.pl \\ ${ }^{2}$ Faculty of Computer Science, Electronics and Telecommunications, \\ Department of Telecommunications \\ Al. A. Mickiewicza 30,30-059 Kraków, Poland, aglowacz@agh.edu.pl
}

\begin{abstract}
Infrared thermography can measure the temperature of a surface remotely. In this article authors present a diagnostic method of incipient fault detection. The proposed approach is based on pattern recognition. It uses monochrome thermal images of the rotor with the application of an area perimeter vector and a Bayes classifier. The investigations have been carried out for direct current motor without faults and motor with shorted rotor coils. The measurements were performed in the laboratory. The efficiency of recognition using the area perimeter vector and the Bayes classifier was $100 \%$. The investigations show that the method based on recognition of thermal images can be profitable for engineers. The proposed method can be applied in mining, metallurgy, fuel industry and in factories where electrical motors are used.
\end{abstract}

Keywords: Thermal image, fault detection, identification methods, pattern recognition.

\section{INTRODUCTION}

$\mathrm{I}_{\mathrm{ten}}^{\mathrm{N}}$ NFRARED THERMOGRAPHY can measure the temperature of a surface remotely. This type of energy is emitted by matter as a result of its temperature. All objects above $0 \mathrm{~K}$ (absolute zero) emit this type of radiation. It is the result of thermally excited electron oscillations and transitions within the matter. Thermal radiation can be viewed as a surface phenomenon, because radiation is emitted from the molecules.

Direct current (DC) motors are designed to operate below a designated temperature (Fig.1.). Generally, the insulation life is decreased when temperature is increased. For this reason an overheated motor can be diagnosed by thermal images [1].

Rotating machines are often used in industry. Development of new materials and their properties is important for the diagnostics of such machines [2-4]. There is also a wide research field on the development of methods for incipient fault diagnostics. Fault diagnostics in rotating machines is mainly carried out through vibration, electrical, acoustic, and thermal analysis [5-24].

Thermal signals were used to identify overheated zones on machinery associated with faults. In the literature the results of the application of selected methods of thermogram analysis were presented [25]. Recognition of monochrome thermal images of electric motor was also discussed in the literature [26], [27]. A system for the diagnosis of the rotor bars of the induction motor was also shown in the literature. This system used spectral analysis and backpropagation neural network [10]. These analyses were conducted for synchronous and induction motors. It is a reason to analyze thermal images of a DC motor.

Methods of image processing were also described [28-29].
The number of interesting image processing methods is growing. The purpose of research is to combine selected methods with thermal imaging. Thermal imaging systems enable localization of overheated zones in motors associated with faults. Thermal phenomena are essential for the following reasons:

(1) The windings dissipate power,

(2) Increased resistance causes a loss of electrical energy,

(3) The higher temperature of motors accelerates the aging process,

(4) Overheated components of motors can cause delays.

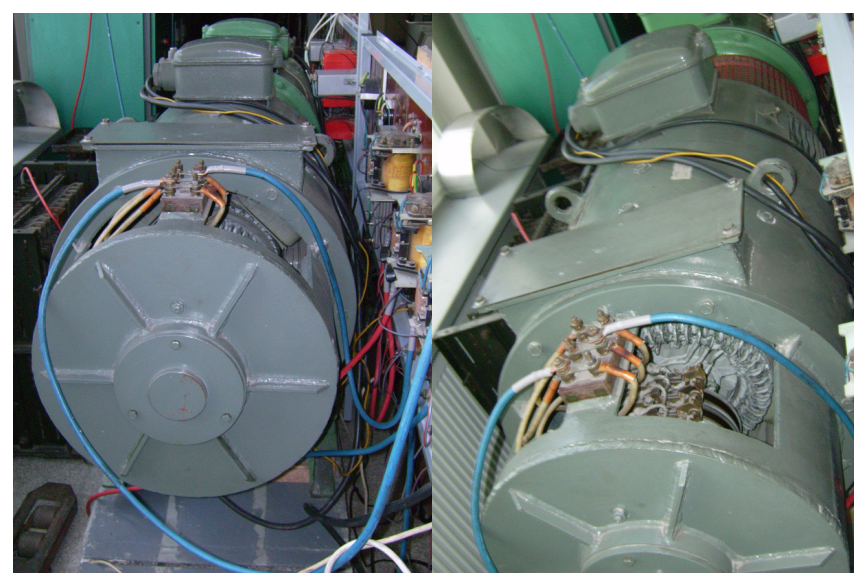

Fig.1. Analyzed direct current motor.

In this work authors present the method of incipient fault diagnostics of a DC motor. The proposed approach is based on pattern recognition. It uses monochrome thermal images of the rotor with the application of an area perimeter vector and a Bayes classifier. 


\section{THE PROCESS OF RECOGNITION OF THERMAL IMAGES OF DC} MOTOR

The process of recognition of thermal images has two phases. The first phase is a pattern creation process (Fig.2.). The second phase is an identification process.

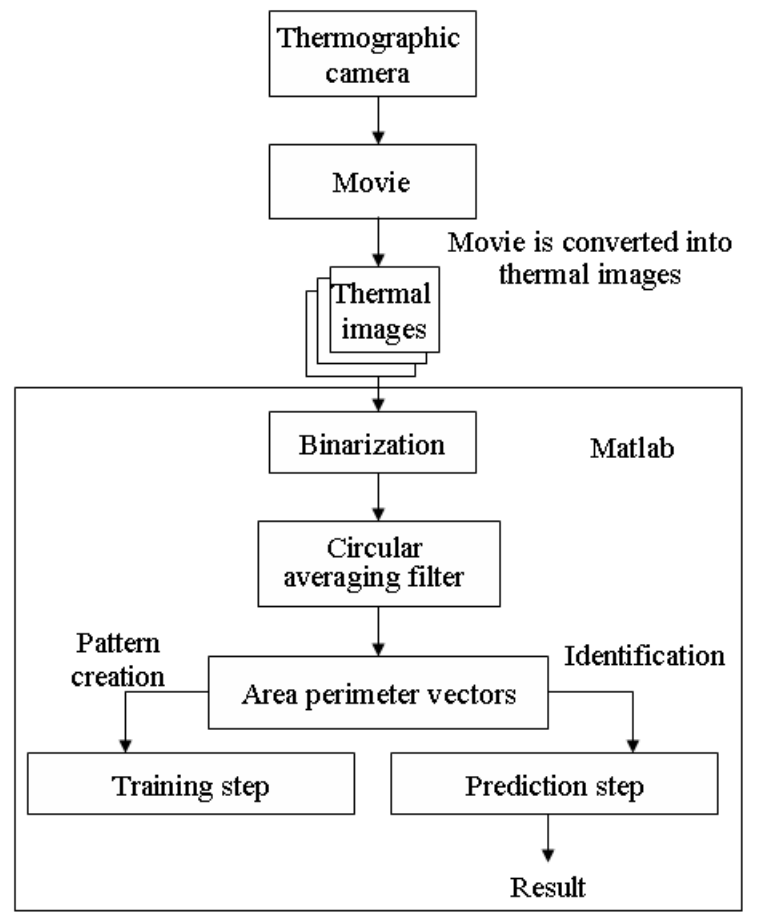

Fig.2. The process of recognition of thermal image of a DC motor with the use of an area perimeter vector and the Bayes classifier.

Methods of image processing are used during these processes. A video sequence is recorded within the computer's memory at the beginning of the pattern creation process. Next, monochrome thermal images are extracted from recording. A training set and a test set contained extracted thermal images. These images are converted through a binarization algorithm. After that, a circular averaging filter is used. Afterwards, area perimeter vectors are calculated. Next the training step of the Bayes classifier is carried out

The first steps of the identification process are the same as for the pattern creation process (binarization, circular averaging filter, area perimeter vectors). The last step of the identification process is the prediction step of the Bayes classifier.

\subsection{Video sequence recording}

A thermographic camera detects thermal radiation. Based on detected temperature of the object's surface, the thermographic cameras can create a thermal image. Usually the higher an object's temperature is, the more thermal energy this object emits. The thermographic camera was installed 0.25 above rotor of the direct current motor during the investigations (Fig.3.). Thermal analysis is performed using a thermographic camera and PC image analysis software. Grayscale images are recorded at a resolution of $256 \times 256$ pixels. a)

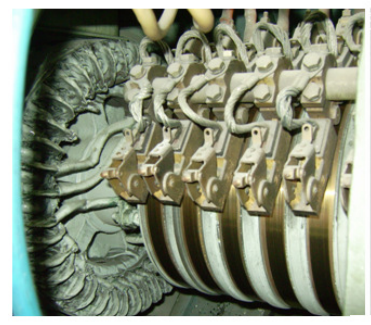

b)

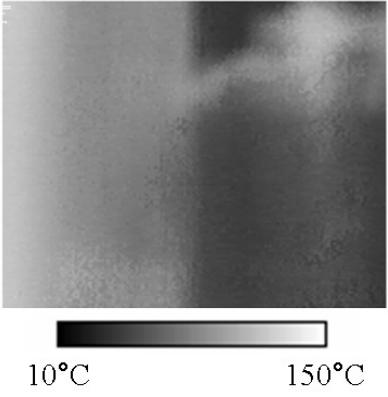

Fig.3. a) Rotor of DC motor with shorted rotor coils, b) thermal image of rotor of DC motor with shorted rotor coils.

These images had 256 colors (resolution of 8 bits, values 0-255). After that, the video recording was stored on a PC (filesystem) in AVI format (Audio Video Interleave).

\subsection{Acquisition of thermal images}

25 monochrome thermal images are included in the video recording with duration of 1 second. A program in the Perl language extracts a single thermal image from the video. The program also uses mplayer library. Obtained thermal images have a resolution of $256 \times 256$ pixels. Thermal images were made under laboratory conditions.

\subsection{Binarization}

The first step of image processing is binarization. It converts a grayscale image into a binary image. The brighter pixels of grayscale image form an object when values of pixels are greater than the specific threshold value. This method of binarization is called threshold above. a)

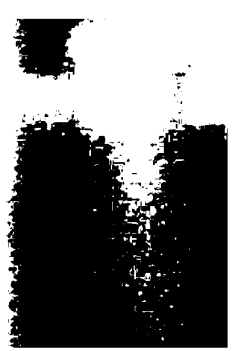

c)

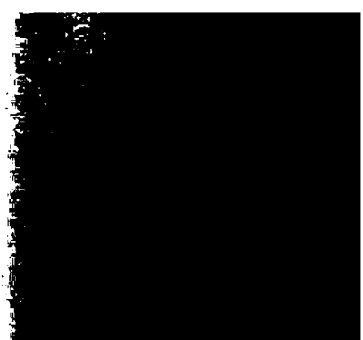

b)

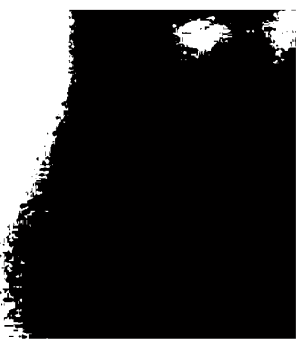

d)

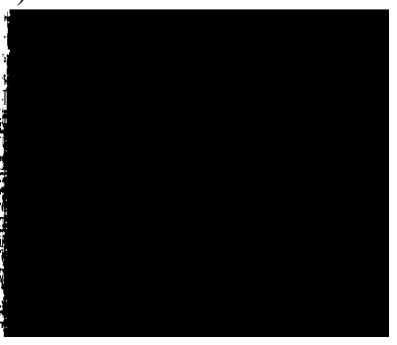

Fig.4. a) Thermal image of rotor of a faultless DC motor after binarization with threshold above $0.36, b$ ) thermal image of rotor of a faultless DC motor after binarization with threshold above 0.46 , c) thermal image of rotor of a faultless DC motor after binarization with threshold above $0.56, \mathrm{~d}$ ) thermal image of rotor of a faultless DC motor after binarization with threshold above 0.66 . 
The method opposite of the above mentioned is called threshold below. Another method of binarization is called threshold inside. In this method pixels form a white object when values of pixels are between two specific thresholds. When binarization is finished white pixels (values 1) and black pixels (values 0) are obtained [30]. In this work authors used the method of binarization - threshold above (Fig.4., Fig.5.) a)

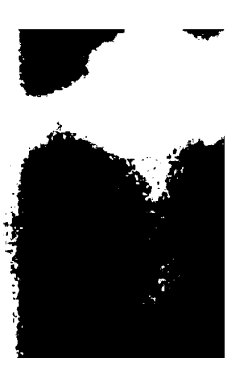

c)

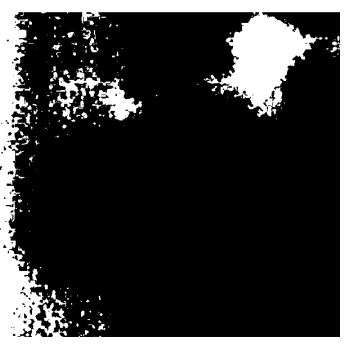

d)
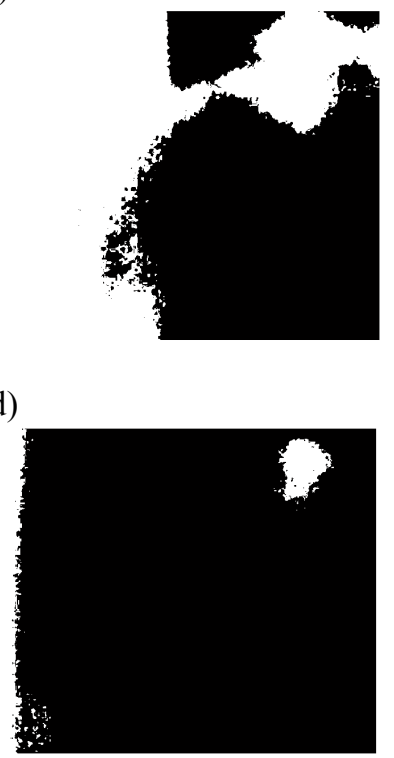

c)

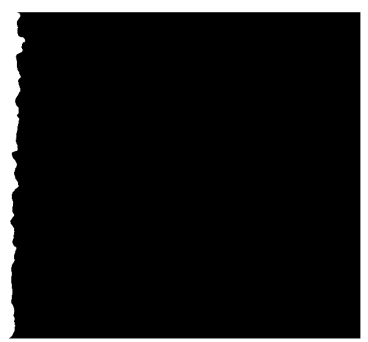

d)

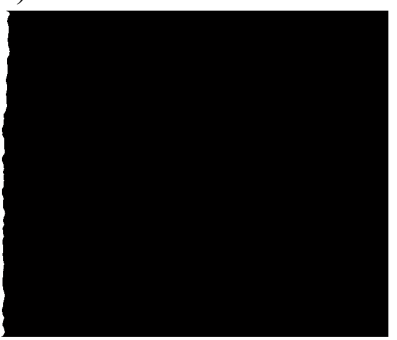

Fig.6. a) Thermal image of the rotor of a faultless DC motor after binarization with threshold above 0.36 and circular averaging filter, b) thermal image of the rotor of a faultless DC motor after binarization with threshold above 0.46 and circular averaging filter, c) thermal image of the rotor of a faultless DC motor after binarization with threshold above 0.56 and circular averaging filter, d) thermal image of the rotor of a faultless DC motor after binarization with threshold above 0.66 and circular averaging filter. a)

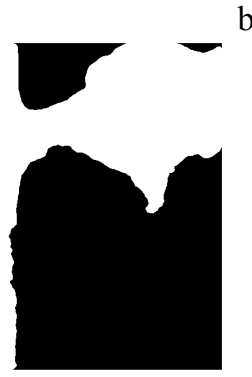

c)

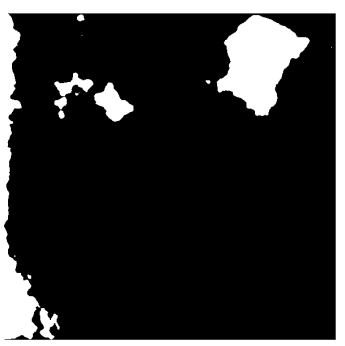

b)

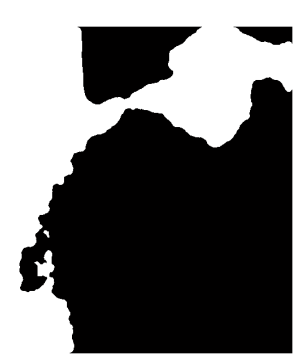

d)

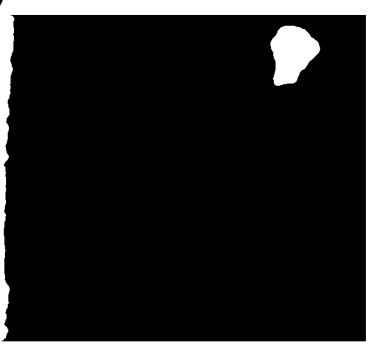

The threshold values of the binarization method were within the range of $<0.36,0.81>$.

\subsection{Circular averaging filter}

A circular averaging filter is useful for smoothing thermal images. Filling holes in the image is one of the main advantages of using this filter [31]. A circular averaging filter uses a square matrix of side 11 (pixels). Thermal images of a DC motor with binarization and a circular averaging filter were shown in Fig.6., Fig.7. a)

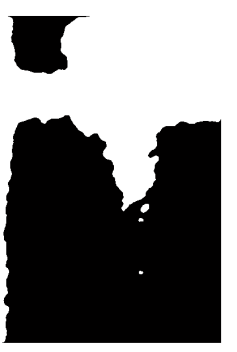

b)

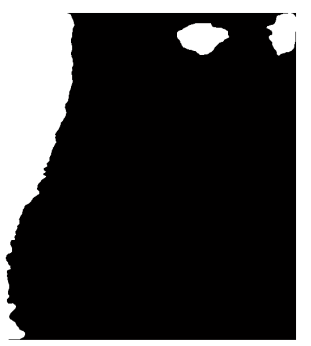

Fig.7. a) Thermal image of the rotor of a DC motor with shorted rotor coils after binarization with threshold above 0.36 and circular averaging filter, b) thermal image of the rotor of a DC motor with shorted rotor coils after binarization with threshold above 0.46 and circular averaging filter, c) thermal image of the rotor of a DC motor with shorted rotor coils after binarization with threshold above 0.56 and circular averaging filter, d) thermal image of the rotor of a DC motor with shorted rotor coils after binarization with threshold above 0.66 and circular averaging filter.

\subsection{Area perimeter vector}

Each sample which is used in the pattern creation and the identification process produces a black and white image. This image contains white objects. Areas and perimeters of white objects are calculated. These 2 values form an area perimeter vector (area - sum of white pixels, perimeter length of object perimeter). Perimeters of white objects are shown in Fig.8. - Fig. 11. 
a)

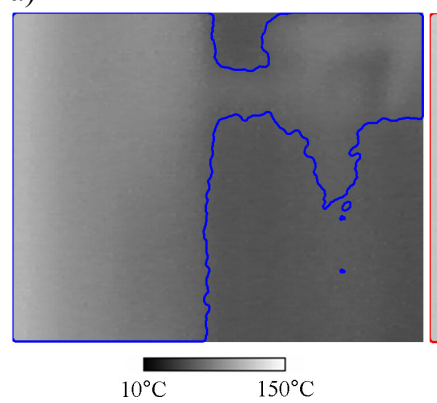

b)

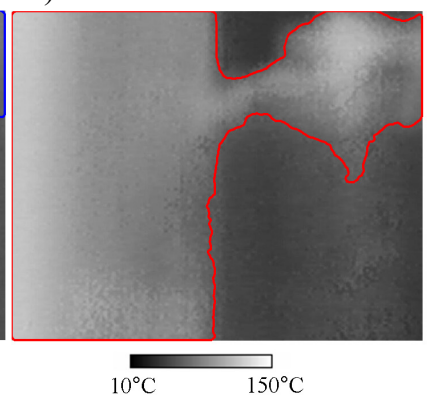

Fig.8. a) Area and perimeter of thermal image of the rotor of a faultless DC motor after binarization with threshold above 0.36 and circular averaging filter, b) area and perimeter of thermal image of the rotor of a DC motor with shorted rotor coils after binarization with threshold above 0.36 and circular averaging filter.

a)

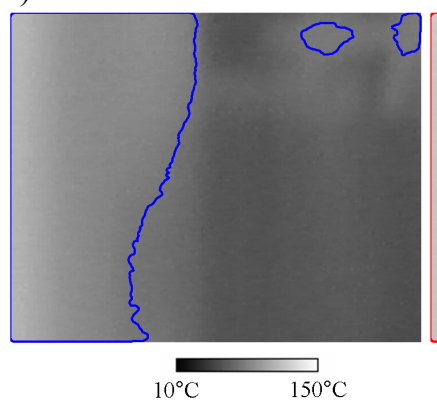

b)

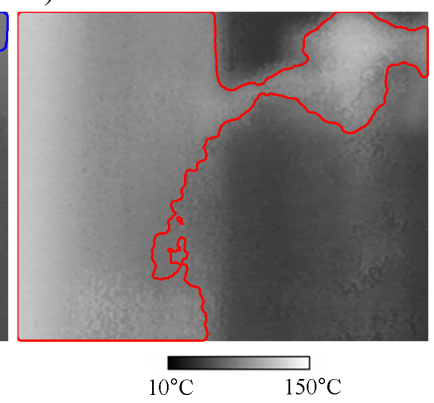

Fig.9. a) Area and perimeter of thermal image of the rotor of a faultless DC motor after binarization with threshold above 0.46 and circular averaging filter, b) area and perimeter of thermal image of the rotor of a DC motor with shorted rotor coils after binarization with threshold above 0.46 and circular averaging filter.

a)

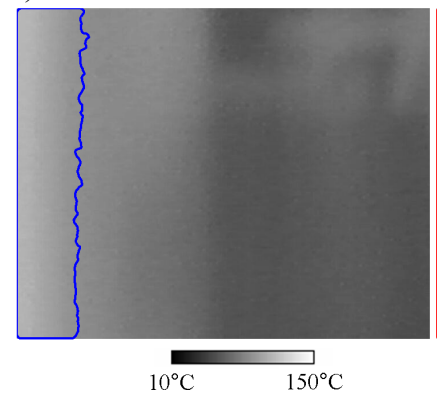

b)

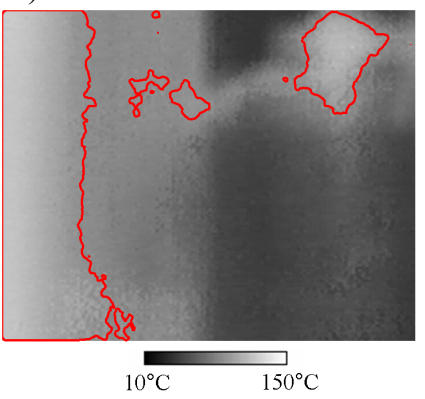

Fig.10. a) Area and perimeter of thermal image of the rotor of a faultless DC motor after binarization with threshold above 0.56 and circular averaging filter, b) area and perimeter of thermal image of the rotor of a DC motor with shorted rotor coils after binarization with threshold above 0.56 and circular averaging filter. a)

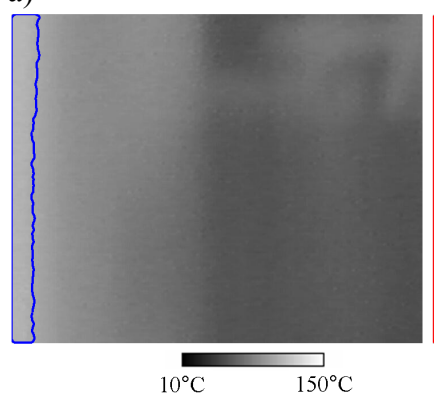

b)

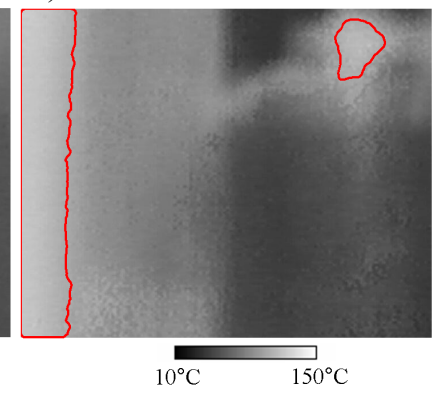

Fig.11. a) Area and perimeter of thermal image of the rotor of a faultless DC motor after binarization with threshold above 0.66 and circular averaging filter, $b$ ) area and perimeter of thermal image of the rotor of a DC motor with shorted rotor coils after binarization with threshold above 0.66 and circular averaging filter.

\subsection{Bayes classifier}

Recently, many classification methods were developed in the literature [32-45]. The artificial intelligence in diagnostics of electric machines was discussed [15], [25].

In this approach, the Bayes classifier is used. This classifier is an efficient learning method for machine learning. This approach uses statistical parameters. These parameters are associated with a posterior probability. This probability quantifies the degree of belief in the different values. Posterior probability is defined as:

$$
p\left(c_{j} \mid d\right)=\frac{p\left(d \mid c_{j}\right) p\left(c_{j}\right)}{p(d)}
$$

where $p\left(c_{j} \mid d\right)$ - probability of instance $d$ being in class $c_{j}$ (Posterior probability); $p\left(d \mid \mathrm{c}_{j}\right)$ - probability of generating instance $d$ given class $c_{j}$; $p\left(c_{j}\right)$ - probability of occurrence of class $c_{j} ; p(d)$ - probability of instance $d$ occurring.

The Bayes classifier assumes attributes that have independent distributions. For this reason, there is the following formula:

$$
p\left(d \mid c_{j}\right)=p\left(d_{1} \mid c_{j}\right) p\left(d_{2} \mid c_{j}\right) \ldots p\left(d_{n} \mid c_{j}\right)
$$

This classifier assumes that features of feature vector are not related to other features. As a result, it requires a small amount of training data to classify the data. Classifier uses two steps:

- Training step: parameters of a probability distribution are estimated with the use of the training samples.

- Prediction step: probability of the test sample belonging to specific class is computed.

Test sample is classified according to the higher posterior probability [31], [40]. 


\section{THE PROCESS OF RECOGNITION OF THERMAL IMAGES OF DIRECT CURRENT MOTOR}

Two different classes of thermal images were analyzed. These classes are defined as follows: faultless DC motor (Fig.12.), and DC motor with shorted rotor coils (Fig.13.).

The analyzed DC motor was connected with external resistance. This served as protection of the rotor windings of the motor. The operation parameters of the DC motor were: $U_{E N V D C}=220 \mathrm{~V}, I_{E N C D C}=4 \mathrm{~A}, U_{N R V D C}=75 \mathrm{~V}, I_{N R C D C}=$ $200 \mathrm{~A}, n_{S}=700 \mathrm{rpm}, P_{M}=13 \mathrm{~kW}$,

where: $U_{E N V D C}$ - excitation nominal voltage of motor, $I_{E N C D C}$ - excitation nominal current of motor, $U_{N R V D C}$ - nominal rotor voltage of motor, $I_{N R C D C}$ - nominal rotor current of motor, $n_{S}$ - rotor speed, $P_{M}$ - motor power.

Each group of three loop rotor coils of a DC motor was shorted with the use of resistance $R_{S C}=7.7 \mathrm{~m} \Omega$.

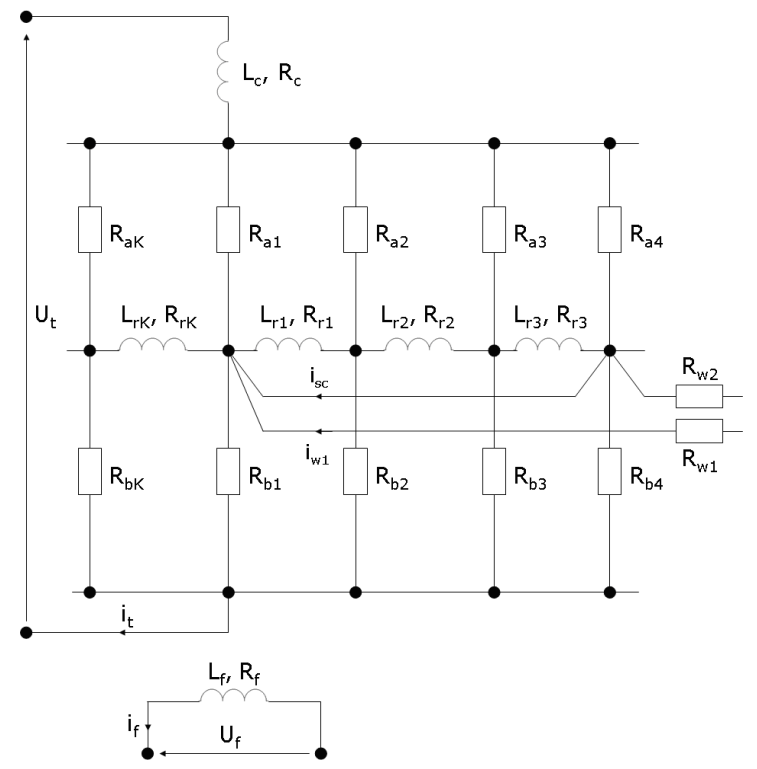

Fig.12. Scheme of rotor winding of a faultless DC motor.

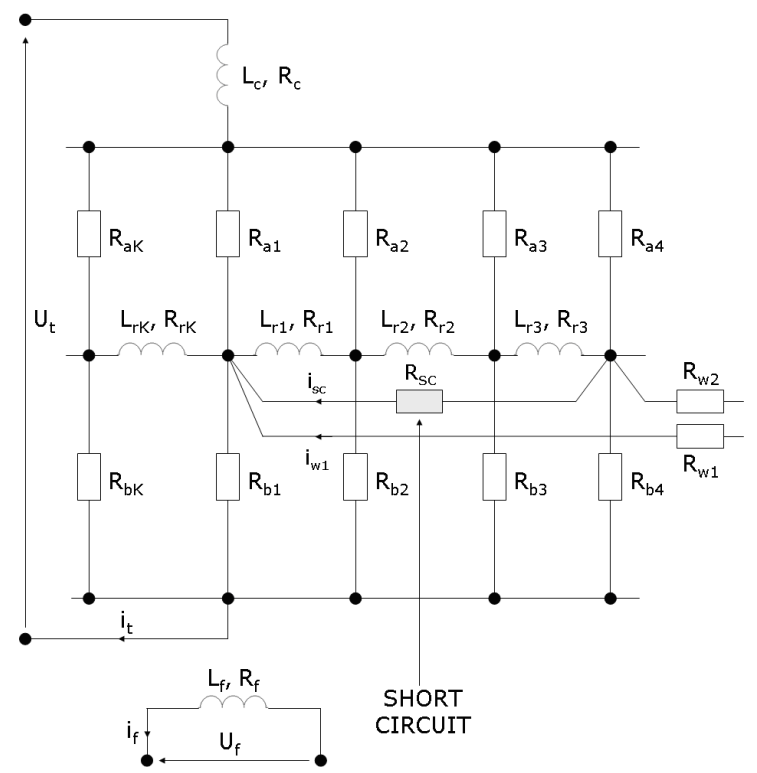

Fig.13. Scheme of rotor winding of a DC motor with shorted coils.
The measurements were performed in the laboratory of electrical machines. Two video sequences were recorded. These recordings contained thermal images of a faultless DC motor and a DC motor with shorted rotor coils. 20 monochrome thermal images were used in the pattern creation process. 100 monochrome thermal images were applied in the identification process. Efficiency of thermal image recognition is defined as:

$$
T=\frac{N C I T I}{N A T I} 100 \%
$$

where: $T$ - efficiency of thermal image recognition, $N C I T I-$ number of correctly identified test images, NATI - number of all test images.

Efficiency of thermal image recognition of a DC motor depending on binarization threshold was presented (Fig.14.).

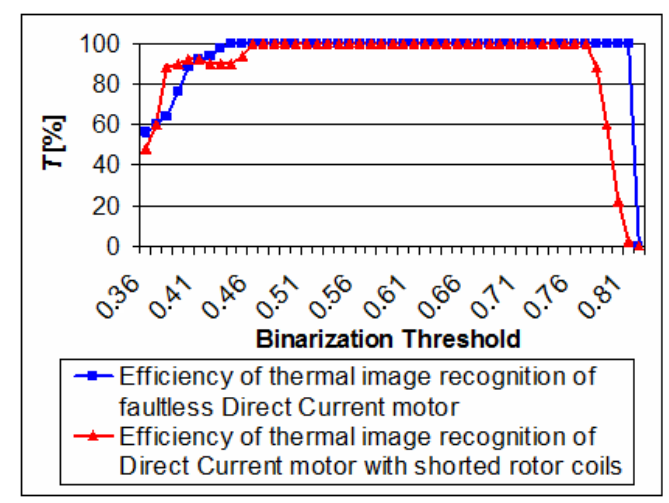

Fig.14. Efficiency of thermal image recognition of a DC motor depending on binarization threshold

The best results were obtained for binarization threshold in the range $<0.46,0.66>$. When binarization threshold was 0.81 , the black image and $T=0 \%$ were obtained.

\section{DISCUSSION}

The main challenge for the system is the number of faulty states of the DC motor being recognized. It was found that good results for two states of direct current motor (faultless motor and motor with shorted rotor coils) can be obtained. Another issue is the number of DC motors. In this paper, one DC motor was analyzed. The best idea is to consider numerous machines and various states of machines.

The first problem is access to a large number of machines. This is a real problem, because it requires strict cooperation with industry and machine operators. Moreover, a construction scheme of each machine is required. It should be defined what faults to look for after access to such a machine is granted. Real experiments with machines and time to prepare controlled faults are also necessary. Many different parameters of direct current motors like currents, voltages, power, and speed of rotation make for a very timeconsuming task.

The second problem is that long durations of shorted rotor coils can cause permanent damage to a DC motor. This requires at the minimum, accessibility of spare parts or an electric motor replacement. 
The third problem is the time it takes (about 30 seconds) to heat up rotor coils. This is a problem for the early diagnostic system. In some cases after such duration the machine can accumulate a lot of damage.

The next problem is that the surface of the rotors should be free of moisture and dirt. In one proposed approach, thermal images were made under laboratory conditions consequently, the system was working well.

There are some considerations on environment conditions. Water vapor, carbon dioxide and other molecules can cause partial heat absorption or dispersion before it reaches the image sensor. Thermal image quality is also dependent on overall surroundings and general temperature. In the future, the authors plan to analyze electric machines in various weather conditions, varying temperature, humidity, etc.

The last issue is the cost of the sensors. The cheapest thermographic camera in the market costs about $\$ 1000$. In comparison, a digital voice recorder costs about $\$ 100$.

\section{APPLICATION}

The proposed method is applied in the following monitoring architecture (Fig.15.). The system takes advantage of an integrated IP camera that performs as a thermal image sensor for the presented thermal diagnostics method, an intermediate node for other sensors, and an advanced data server for transferring measurements to a network database. The number of such devices constitutes a monitoring network in which multiple objects (machines) can be supervised by the operator in remote locations or with the use of an external alarm system (e.g., via GSM network).

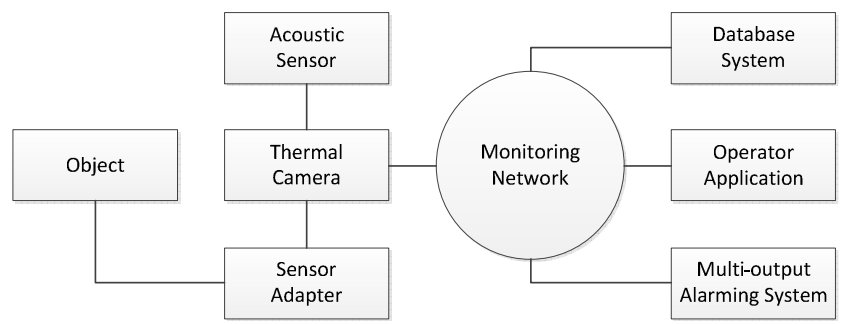

Fig.15. Monitoring system architecture.

The presented architecture enables a fully automatic diagnostics process with the application of the proposed thermal recognition method. Additional analog sensors can be connected through a dedicated sensor adapter. It has been developed in hardware for collecting measurements and it interconnects to the camera using RS-485 interface. Such elementary sensors can directly measure objects and environment properties, e.g., temperature, humidity, vibrations, etc., in order to support the whole decisionmaking system.

The development of such a system also requires implementation of a dedicated operator application, which was obtained from the LabView environment.

The use of a RS-485 terminal enables covering the area within the distance of over $100 \mathrm{~m}$ between the camera and additional sensors (that is, however, limited for the presented method by an effective video recording range).
An acoustic sensor is connected to the built-in external line input of a camera. Network integration is achieved on the basis of IP protocol and standard network interfaces. This approach provides a convenient way of transmitting digital images and measurement data.

The thermal network camera used in the experiments contained an uncooled micro bolometer sensor in spectral range $8-14 \mu \mathrm{m}$ with a sensitivity of $0.1 \mathrm{~K}$, in water-proof outdoor casing with a germanium window.

\section{CONCLUSIONS AND FUTURE WORK}

The application of infrared thermography is essential for diagnostics of DC motors. This technique is helping engineers to predict any incipient failure. This ensures equipment safety and saves production loss. In this paper the method and the system of recognition of thermal images of a DC motor were shown.

The investigations have been carried out for a DC motor without faults and a motor with shorted rotor coils. The results of recognition using an area perimeter vector and the Bayes classifier were $100 \%$ (for two classes). The investigations show that the method based on recognition of thermal images can be profitable for engineers. The proposed method can be used in mining, metallurgy, fuel industry, and in factories where electrical motors are used. Unfortunately, it takes time to heat the rotor of a machine and the proposed method is not as fast as other methods of diagnostic such as: methods based on electrical or acoustic signals.

In the near future, new applications of recognition of thermal images will be developed. There is also an idea to use thermographic images, vibrations, acoustic, and electrical signals together.

\section{ACKNOWLEDGMENTS}

This work has been partly supported by AGH University of Science and Technology, grant Nr. 11.11.120.612, grant Nr. 11.11.230.018 and grant Nr. 11.11.120.354.

\section{REFERENCES}

[1] Kennedy Space Center. (2012). Thermography Technique AT-9.

[2] Tokarski, T., Wzorek, L., Dybiec, H. (2012). Microstructure and plasticity of hot deformed 5083 aluminum alloy produced by rapid solidification and hot extrusion. Archives of Metallurgy and Materials, 57 (4), 1253-1259.

[3] Krolczyk, G.M., Legutko, S. (2014). Experimental analysis by measurement of surface roughness variations in turning process of duplex stainless steel. Metrology and Measurement Systems, 21 (4), 759. 770.

[4] Koscielny, J.M., Syfert, M. (2014). Application properties of methods for fault detection and isolation in the diagnosis of complex large-scale processes. Bulletin of The Polish Academy of Sciences-Technical Sciences, 62 (3), 571-582.

[5] Umasankar, L., Kalaiarasi, N. (2014). Internal Fault Identification and Classification of Transformer with 
the Aid of Radial Basis Neural Network (RBNN). Arabian Journal for Science and Engineering, 39 (6), 4865-4873.

[6] Glowacz, A. (2014). Diagnostics of synchronous motor based on analysis of acoustic signals with the use of line spectral frequencies and K-nearest neighbor classifier. Archives of Acoustics, 39 (2), 189-194.

[7] Glowacz, A., Glowacz, W., Glowacz, Z. (2015). Recognition of armature current of DC generator depending on rotor speed using FFT, MSAF-1 and LDA. Eksploatacja i Niezawodnosc-Maintenance and Reliability, 17 (1), 64-69.

[8] Pleban, D. (2014). Definition and measure of the sound quality of the machine. Archives of Acoustics, 39 (1), 17-23.

[9] Sebok, M., Gutten, M., Kucera, M. (2011). Diagnostics of electric equipments by means of thermovision. Przeglad Elektrotechniczny, 87 (10), 313-317.

[10] Glowacz, W. (2013). Diagnostics of induction motor based on spectral analysis of stator current with application of backpropagation neural network. Archives of Metallurgy and Materials, 58 (2), 559562.

[11] Baranski, M., Decner, A., Polak, A. (2014). Selected diagnostic methods of electrical machines operating in industrial conditions. IEEE Transactions on Dielectrics and Electrical Insulation. 21 (5), 20472054.

[12] Zuber, N., Bajric, R., Sostakov, R. (2014). Gearbox faults identification using vibration signal analysis and artificial intelligence methods. Eksploatacja $i$ Niezawodnosc-Maintenance and Reliability, 16 (1), 61-65.

[13] Zhang, J.H., Ma, W.P., Lin, J.W., Ma, L., Jia, X.J. (2015). Fault diagnosis approach for rotating machinery based on dynamic model and computational intelligence. Measurement, 59, 73-87.

[14] Baranski, M. (2014). New vibration diagnostic method of PM generators and traction motors - detecting of vibrations caused by unbalance. In IEEE International Energy Conference (ENERGYCON), 13-16 May 2014. IEEE, 28-32.

[15] Swedrowski, L., Duzinkiewicz, K., Grochowski, M., Rutkowski, T. (2014). Use of neural networks in diagnostics of rolling-element bearing of the induction motor. Key Engineering Materials, 588, 333-342.

[16] Lu, C., Tao, X.C., Zhang, W.J., Wang, Z.L. (2014). Machine integrated health models for condition-based maintenance. Tehnicki Vjesnik-Technical Gazette, 21 (6), 1377-1383.

[17] Gornicka, D. (2014). Vibroacoustic symptom of the exhaust valve damage of the internal combustion engine. Journal of Vibroengineering, 16 (4), 19251933.

[18] Glowacz, A., Glowacz, A., Korohoda, P. (2012). Recognition of color thermograms of synchronous motor with the application of image cross-section and linear perceptron classifier. Przeglad Elektrotechniczny, 88 (10A), 87-89.

[19] Wegiel, T., Sulowicz, M., Borkowski, D. (2007). A distributed system of signal acquisition for induction motors diagnostic. In IEEE International Symposium on Diagnostics for Electric Machines, Power Electronics \& Drives, 6-8 September 2007. IEEE, 88-92.

[20] Rusinski, E., Moczko, P., Odyjas, P., Pietrusiak, D. (2014). Investigation of vibrations of a main centrifugal fan used in mine ventilation. Archives of Civil and Mechanical Engineering, 14 (4), 569-579.

[21] Andonova, A.V., Hinov, N.L. (2014). Thermographic analysis of a bridge power converter. Journal of Electrical Engineering-Elektrotechnicky Casopis, 65 (6), 371-375.

[22] Duspara, M., Sabo, K., Stoic, A. (2014). Acoustic emission as tool wear monitoring. Tehnicki VjesnikTechnical Gazette, 21 (5), 1097-1101.

[23] Zhao, Z., Wang, C., Zhang, Y.G., Sun, Y. (2014). Latest progress of fault detection and localization in complex electrical engineering. Journal of Electrical Engineering-Elektrotechnicky Casopis, 65 (1), 55-59.

[24] Abramov, I.V., Nikitin, Y.R., Abramov, A.I., Sosnovich, E.V., Bozek, P. (2014). Control and diagnostic model of brushless DC motor. Journal of Electrical Engineering-Elektrotechnicky Casopis. 65 (5), 277-282.

[25] Glowacz, A., Glowacz, A., Glowacz, Z. (2014). Recognition of monochrome thermal images of synchronous motor with the application of quadtree decomposition and backpropagation neural network. Eksploatacja $i$ Niezawodnosc - Maintenance and Reliability, 16 (1), 92-96.

[26] Glowacz, A., Glowacz, A., Korohoda, P. (2014). Recognition of monochrome thermal images of synchronous motor with the application of binarization and nearest mean classifier. Archives of Metallurgy and Materials, 59 (1), 31-34.

[27] Glowacz, A., Glowacz, A., Glowacz, Z. (2015). Recognition of monochrome thermal images of synchronous motor with the application of skeletonization and classifier based on words. Archives of Metallurgy and Materials, 60 (1), 27-32.

[28] Stepien, K. (2014). Research on a surface texture analysis by digital signal processing methods. Tehnicki Vjesnik-Technical Gazette, 21 (3), 485-493.

[29] Fidali, M., Urbanek, G. (2012). The application of evolutionary algorithms in the search of relevant statistical features of infrared images. Qirt Journal, 9 (1), 33-54.

[30] Shapiro, L.G., Stockman, G.C. (2002). Computer Vision. Prentice Hall.

[31] MathWorks. (2015). MATLAB and SimuLink for Technical Computing. www.mathworks.com.

[32] Hachaj, T., Ogiela, M.R. (2013). Application of neural networks in detection of abnormal brain perfusion regions. Neurocomputing, 122 (Special Issue), 33-42.

[33] Augustyniak, P., Smolen, M., Mikrut, Z., Kantoch, E. (2014). Seamless tracing of human behavior using 
complementary wearable and house-embedded sensors. Sensors, 14 (5), 7831-7856.

[34] Batko, W., Przysucha, B. (2014). Statistical analysis of the equivalent noise level. Archives of Acoustics, 39 (2), 195-198.

[35] Dudek-Dyduch, E., Tadeusiewicz, R., Horzyk, A. (2009). Neural network adaptation process effectiveness dependent of constant training data availability. Neurocomputing, 72 (13-15), 3138-3149.

[36] Valis, D., Pietrucha-Urbanik, K. (2014). Utilization of diffusion processes and fuzzy logic for vulnerability assessment. Eksploatacja $i$ NiezawodnoscMaintenance and Reliability, 16 (1), 48-55.

[37] Alshayeb, M., Eisa, Y., Ahmed MA. (2014). ObjectOriented Class Stability Prediction: A Comparison Between Artificial Neural Network and Support Vector Machine. Arabian Journal for Science and Engineering, 39 (11), 7865-7876.

[38] Mazurkiewicz, D. (2014). Computer-aided maintenance and reliability management systems for conveyor belts. Eksploatacja $i$ NiezawodnoscMaintenance and Reliability, 16 (3), 377-382.

[39] Kundegorski, M., Jackson, P.J.B., Ziolko, B. (2014). Two-microphone dereverberation for automatic speech recognition of Polish. Archives of Acoustics, 39 (3), 411-420.

[40] Murty, M.N., Devi, V.S. (2011). Bayes classifier.
Pattern Recognition: An Algorithmic Approach. Springer, 86-102.

[41] Krolczyk, G.M., Krolczyk, J.B., Legutko, S., Hunjet, A. (2014). Effect of the disc processing technology on the vibration level of the chipper during operations. Tehnicki Vjesnik-Technical Gazette, 21 (2), 447-450.

[42] Jun, S., Kochan, O. (2014). Investigations of thermocouple drift irregularity impact on error of their inhomogeneity correction. Measurement Science Review, 14 (1), 29-34.

[43] Jaworek-Korjakowska, J., Tadeusiewicz, R. (2014). Determination of border irregularity in dermoscopic color images of pigmented skin lesions. In 36th Annual International Conference of the IEEE Engineering in Medicine and Biology Society (EMBC), 26-30 August 2014. IEEE, 6459-6462.

[44] Krolczyk, J.B. (2014), An attempt to predict quality changes in a ten-component granular system. Tehnicki Vjesnik-Technical Gazette, 21 (2), 255-261.

[45] Dzwonkowski, A., Swedrowski, L. (2012). Uncertainty analysis of measuring system for instantaneous power research. Metrology and Measurement Systems, 19 (3), 573-582.

Received December 4, 2014 Accepted June 23, 2015. 